\title{
Quality of Life in Young Illicit Substance Abuser Men: Testing a Moderated Mediation Model of Age Related Decline in Executive Functions
}

Shameem Fatima ( $\square$ shameemfatima@cuilahore.edu.pk)

COMSATS University Islamabad - Lahore Campus https://orcid.org/0000-0001-8252-0832

Sajid Hassan

University of Management and Technology, Lahore

Farhat Jamil

Beaconhouse National University

\section{Research Article}

Keywords: Inhibition, Cognitive Flexibility, Quality of life, Family History of Substance Use

Posted Date: November 8th, 2021

DOI: https://doi.org/10.21203/rs.3.rs-999218/v1

License: () (i) This work is licensed under a Creative Commons Attribution 4.0 International License. Read Full License 


\section{Abstract \\ Background}

Earlier literature has documented age related decline in executive functions (EF) in normal aging adults, yet it is unclear whether age related EF decline is linked with quality of life (QoL) possibly mediating the link between age and QoL. Therefore, the study hypothesized that selective EF components would mediate the association between age and QoL domains in young substance abuser men and family history of substance use would moderate these mediated associations.

\section{Method}

A sample of 212 young substance abuser men (105 positive family history and 107 negative family history of substance use) performed on performance measures assessing selective EF components-inhibition and cognitive flexibility. Also, they reported their QoL on self-report measure of WHOQOL.

\section{Results}

Mean scores of the sample on all QoL domains were lower than expected by chance. Also, the participants with positive family history of substance use compared to those with negative family history scored significantly lower on all QoL domains except physical QoL. Mediation analyses revealed that of two EF components, only inhibition mediated the negative association of age with psychological, social, and environmental QoL. Furthermore, family history of substance use moderated all the significant mediations with stronger indirect negative associations in participants having a family history of substance use compared to those with no such history.

\section{Conclusion}

It is concluded that inhibitory control, which is vulnerable to aging, substance use, and family history of substance use, is an important factor related to QoL in young substance abuser men.

\section{Introduction}

Substance abuse is an alarming menace that has taken over the world with increasing fervor. United Nations Office on Drug and Crime reports that according to world wide data for 2016, about 275 million people have used illicit substances at least once including 31 million individuals with a substance use disorder requiring treatment and rehabilitation [1]. With substance abuse on the rise, it undoubtedly leaves undesirable consequences for the abusers and society. In essence, quality of life (QoL) as a result of substance abuse is greatly impacted. Quality of life is conceptualized as an individual's perceptions of their position in life in the context of their cultural values and in relation to their goals, expectations, and life standards. It, therefore, encompasses a multidimensional approach assimilating an individual's perception of physical, psychological, social, and environmental wellness. Physical QoL measures facets of energy/fatigue, pain/discomfort, and sleep/rest. Psychological QoL includes feelings, self-esteem, thinking, learning, memory, and concentration. Social QoL domain examines personal relationships, social support, and sexual activity. Environmental QoL refers to facets like financial resources, freedom, physical safety, health and social care, home and physical environment, and opportunities for acquiring new information and skills. It is reflective of the view that QoL imputes to subjective evaluation, which is embedded in cultural, social, and environmental context [2].

\section{Quality of Life in Substance Users and Age Related Changes}

Quality of life has been described as a significant clinical and research outcome in the field of chronic disease management, including substance use disorders $[3,4]$. Available data shows that substance abusers generally report lower QoL compared to general population and those with other serious psychiatric disorders $[5,6]$. Subjective evaluation of QoL also varies with age. Normal aging in older adults is proposed to be associated with decreased QoL [7]. Studies have shown that significant life changes in relation to life course including declining physical and mental health status and changing work and financial status are associated with decreasing QoL and wellbeing [8, 9]. It is proposed that declining health status and associated diminished QoL is featured earlier in substance abusers' lives [10]. In a qualitative study based on a sample of 11 adult substance users, the researchers [11] found that diminished QoL, which was associated with aging, was the prominent feature for most of those interviewed. Similarly, in another study, younger (26-years) compared to older group of men (26+ years) with opioid use disorder reported more mental health problems [12]. Accordingly, assessing decreasing QoL with increasing age in young substance abuser samples needs attention of researchers because research addressing this topic in young illicit substance abuser men from Asian region is almost lacking.

\section{Age Related Weakening of EF in Substance Abusers}

Substance abuse has been characterized by diminished EF. For example, in a comparative study, adults with polysubstance abuse scored low on all EF measures on BRIEF inventory compared to healthy control [13]. Declining EF abilities in aging adults are also a focus of researchers on the other hand [1416]. The EF processes including cognitive flexibility, inhibition, and working memory show a clear age-related decline in adults [15-17]. As discussed earlier, the impact of aging on EF may begin earlier in substance abusers because substance abuse experience may speedup deterioration of physical and mental health capacities. Probably, EF decline starts earlier in young adulthood years in substance abusers. Empirical evidence supports diminished EF abilities in young 
substance abusers compared to healthy controls [18]. However, little data is available on age related decline in EF in young adult samples of substance abusers.

\section{Associations between Age, EF, and QoL}

Thus, it appears that substance abusers present weaker EF abilities and report poorer QoL compared to general population. Age related changes in EF may in turn substantially influence QoL. Yet, currently, there is little evidence regarding the association of EF with QoL in substance abuser population. Nonetheless, the evidence based on normal and diverse clinical samples supports the connection of EF with QoL as well as with psychological wellbeing in terms of emotional and social adjustment [19-23]. Presently, the studies are focusing on age related decline in EF and QoL in healthy aging adults on one hand [15], and on the EF-QoL link in healthy and clinical samples on the other hand [21,23]. However, evidence for the link between EF and QoL is lacking for samples of illicit substance abusers. Also, the mediational associations between age-EF-QoL in illicit substance abusers, is another topic that requires additional attention of researchers. Accordingly, the study formulates its first hypothesis to assess whether age related decline in EF mediates the age-QoL link ( $\mathrm{H} 1$ ). The direct support for the proposed mediation model is not available in empirical literature but a remotely related study found that EF mediated the association of traumatic experience with posttraumatic stress symptoms for youth exposed to complex trauma [24].

\section{Family History as a Moderator}

Beyond age related linear changes in EF and QoL in adults, the age related decline in EF in substance abusers may also depend on other personal and familial factors. Family history of substance use can be an important factor which may likely moderate the proposed mediated age-EF-QoL link. Studies have shown that family history of substance use interacts significantly with frequency of substance use [25] and substance dependence [26] to predict neuropsychological functioning and EF. In light of these findings, it is presumed that family history of substance use may interact with age to predict EF and to moderate the ageEF-QoL mediated link given that the speed of age-related changes in EF may not be similar across groups with and without family history. This may lead to a differential cognitive explanation of the age-QoL link for both groups. Therefore, the study formulates a secondary hypothesis to assess whether the meditational associations between age, EF, and QoL would differ across substance abusers with and without family history of substance use (H2). Assessing these objectives on a sample of Pakistani illicit substance abuser men becomes a prime concern given the data showing increasing rates of substance users in Pakistan [27]. Moreover, keeping the former and latter Western research findings in sight, a dearth of indigenous literature from this region pertaining to these domains is evident and in dire need of being fulfilled. A hypothesized model has been shown in Figure 1.

\section{Method}

\section{Participants}

The selected sample included $212(\mathrm{FH}+=107 ; \mathrm{FH}-=105)$ inpatient illicit substance abuser men in age range from 19 to 40 years $(\mathrm{M}=27.61 \& \mathrm{SD}=5.38)$. The sample were selected from drug wards/drug rehabilitation centers of government and private hospitals from Lahore, the second largest metropolitan city in Pakistan and the fifth largest city in South Asian region with more than 12 million population. Inclusion criteria included being young adults and illicit substance users, having a minimum of primary education, being able to read or understand Urdu language, and detoxified with managed withdrawal symptoms. Participants having a history of any co-morbid psychiatric diagnosis or neurological disorder, physical conditions associated with withdrawal state such as pain, or being in disoriented state were not included in the study. Keeping in view the inclusion and exclusion criteria, the participants were selected with an assistance of the clinical psychologists working in the selected hospitals. All the participants were detoxified, under treatment, and in a controlled environment. Demographic characteristics of the sample are presented in Table 1.

\section{Assessment Measures}

\section{Executive Functions}

The study used two scales namely Color Word Interference Test and Design Fluency Test from a test battery named Delis Kaplan Executive Functions SystemDKEFS [28]. The Color Word Interference Test consisted of four separate conditions. Conditions 1 and 2 tested primary visual, perceptual, and linguistic abilities; and conditions 3 and 4 assessed inhibition, an executive skill. Task completion time and number of errors on each of the four conditions were taken as two response measures of inhibition on the test. Before calculating two composite time and error scores, the individual scores were reversed. The composite score thus obtained represented higher levels of inhibition from higher composite scores. Later on, looking at the high correlation between time and error measures of inhibition $(r=.72, p<.001)$, scores on both measures were combined to give a composite score of inhibition. Keeping in view the different score ranges on both time and error raw scores, the two scores were first standardized before calculating a composite score of inhibition.

The Design Fluency Test comprising three conditions: basic, filter, and switch assessed cognitive flexibility, an executive ability. The respondent was required to draw different designs by observing some rules. The response measure on this test was number of correct designs drawn within a 60 seconds time period on each of the three conditions. The composite score obtained by adding scores on 3 conditions represented a higher level of cognitive flexibility from a higher score. Considering the unavailability of norms on DKEFS tests for Pakistani participants, the raw scores on both DKEFS tests were used for data analyses.

\section{World Health Organization-Quality of life}

The study used the Urdu version of World Health Organization Quality of Life Assessment Instrument-short version 26 items [29] to assess QoL in four domains namely physical, psychological, social, and environmental. First two items of the scale assessed general QoL and general health status; and the rest 24 items assessed four QoL domains. Responses were recorded on a 5 points Likert scale. Higher composite scores represented higher QoL on each respective domain. 


\section{Procedure}

After obtaining approval from the Ethical Review Committee and reviewing all the ethical consideration, the approval for data collection was obtained from the heads of psychiatry wards and rehabilitation centers. Then, potential participants were identified with assistance of the clinical psychologists working in each selected hospital's drug unit. Next, the participants were approached and briefed about the study. After taking their consent, they were assessed on the study measures in individual setting. Order of the scales was counterbalanced across participants to cancel out any effects that might likely arise from scale order.

\section{Results}

Descriptive statistics and differences in scores between participants with and without family history of substance use were calculated on EF measures and QoL domains (see Table 2). The results showed significant group differences on inhibition (time and error measure) and cognitive flexibility measures of EF with participants having a positive family history scoring lower on three EF scores (two inhibition scores and one cognitive flexibility score) representing poorer EF abilities compared to those with a negative family history. Furthermore, participants having a positive family history of substance use scored lower on three of four QoL domains including psychological, social, and environmental as well as on general QoL and general health.

Then, correlations of age and both EF measures with four QoL domains as well as with general health and general QoL were calculated (see Table 3). The results showed that age was a significant negative correlate of three QoL domains including psychological, social, and environmental QoL. Of the two selected EF scores, inhibition was positively correlated with all four QoL domains as well as with general QoL and general health indicating better inhibition ability to be associated with improved QoL and general health. Moreover, cognitive flexibility was positively correlated with psychological, social, and environmental but not with physical QoL. Also, this measure was a positive correlate of general QoL and general health.

Next, to assess the first hypothesis, multimediation models (Model 4 in Process) and to assess the second hypothesis moderated mediation models (Model 7 in Process [30]) were computed to assess the conditional mediating roles of selected EF components (inhibition and cognitive flexibility) in relation between age and QoL domains across two groups of substance abusers, with and without family history of substance use. Raw scores on all variables were first standardized with means $=0$, and $S D=1$, before analyzing the multimediation and moderated mediation models. Considering that age was negatively correlated with three QoL domains (psychological, social, and environmental), multimediation and moderated mediation models were calculated only for these three QoL domains. Also, by considering the significant correlations of demographics, education and duration of substance use were taken as covariates in multimediation and moderated mediation analysis. Results from multimediation models showed that only inhibition out of two EF mediators significantly mediated the negative association of age with psychological, social, and environmental QoL after controlling the confounding due to potential demographics (see Model 4, Table 4). The significant Sobel z value for inhibition as well the total, direct, and indirect effects of inhibition showed that the total effect of age on QoL domains was reduced from -.75, -.60, \& -.30 to -.52, -.30, \& -.27 for psychological, social, and environmental QoL domains respectively (see Figure 2). Cognitive flexibility was initially a significant correlate of both age and the three QoL domains, however, became insignificant mediator in the presence of inhibition. Next, results from the moderated mediation models showed that family history of substance use significantly interacted with age to predict inhibition but not cognitive flexibility, hence significantly moderated the indirect effect of inhibition but not of cognitive flexibility in the mediational links of age with psychological, social, and environmental QoL domains. Further detail of moderated mediational analysis showed that conditional indirect effects of inhibition were stronger for partipants with a positive family history and weaker for those with a negative family history of substance use. Figure 2 also shows that conditional indirect effects of inhibition were stronger for participants with positive family history of substance use compared to those with negative family history.

\section{Discussion}

The objectives of the study were to assess the mediating roles of selective EF components-inhibition and cognitive flexibility-in association between age and QoL domains in young illicit substance abuser men and to assess whether these mediated links would be different across participants having a positive or a negative family history of substance use. Following the first hypothesis of the current study, it was found that age was a negative correlate of psychological, social, and environmental QoL. It is explained that with increasing age in young adulthood years, the social, psychological, and environmental QoL of substance abuser men decreases. This finding is worth discussing in several ways. First, with increasing age, continuing substance use may hamper their psychological and social QoL by weakening their psychological resistance and social bonds given the evidence for social support as a positive correlate of QoL in adult clinical population [31]. Also, financial burden of substance use may hamper their environmental QoL. Mainly, the present study used a sample of men only from a patriarchal culture; it is quite possible that aging would have differential or weak association with QoL in substance abuser women from the same culture, where financial burden is the sole responsibility of men. Keeping in view the cultural norms regarding proscribed use of substance and gender stereotypes, accessibility to substance abuser women was limited. Therefore, considering gender wise non proportionality of the data, women were not included in the study. Second, though the evidence from healthy older adult samples shows decreasing QoL with increasing age [7] but the finding from the current study sample of young substance abuser men have revealed an earlier decline in QoL even during young adulthood years. This finding lines up with study's proposition and with rarely available data $[10,11]$ showing that substance use experience accelerates the effects of aging on QoL. Third, the current finding is different from the prevailing evidence based on studies conducted on typically developing adults which describe young adulthood years to be very productive [32]. This difference may be attributed to substance abuse. This particular finding is an important addition in literature in that it assesses the association of age with QoL on a sample of young substance abusers in contrast to many studies assessing the effects of healthy aging on QoL in older adult samples.

Further, in line with the mediation hypothesis, age was found to be the negative correlate of inhibition and cognitive flexibility in young substance abuser men. Although the evidence from existing literature based on the Western samples shows a decline in EF in mid-twenties in typically developing young adults [33], however, the studies from Asian culture found that EF remain stable during typical young adulthood years [34]. Contrarily, the present study shows a decline in

Page $4 / 10$ 
EF in young substance abusers despite the evidence of stability of EF till mid 40s in the same cultural context [15]. The finding may be justified in that with increasing age continuing substance use may have caused an earlier decline in both EF components in this sample. Young substance abusers may have become slower, took more processing time, and made more errors. Also, it is quite possible that a decline in basic cognitive resources (visual, perceptual, and linguistic abilities) with passing years of substance use might have accounted for this decline in selective EF components. The finding is noteworthy in another way, that is, age is strongly correlated with inhibition indicating that inhibitory control component of EF is more vulnerable to aging compared to cognitive flexibility in substance abuser men.

Pertaining to mediation hypothesis, it was found that inhibition was a strong mediator of the association of age with three QoL domains including psychological, social, and environmental QoL in the current study sample. The results line up with evidence from the previous literature based on other clinical samples that has shown EF to be the positive predictor of QoL [23]. However, no previous study could be seen on substance abuser men assessing these particular associations. The current study provides evidence for the first time that inhibition is a predictor of QoL as well as a mediator of age-QoL link in an Asian sample of young illicit substance abuser men. Currently, on one hand, the literature is available on the age-EF link on different samples and particularly on typically developing older adults [15]; and on the other hand, literature is also available for the EF-QoL link on clinical samples; but the earlier studies have not attempted to examine meditational associations between age, EF, and QoL domains. Importantly, the current study has assessed this objective on a sample of young illicit substance abuser men from a different cultural context, a patriarchic culture from a South Asian region. Notably, lining up with the existing literature on EF [15,23], cognitive flexibility was a correlate of age and QoL domains, however, became an insignificant meditator in the presence of inhibition, a more powerful mediator.

A secondary hypothesis was examined to assess the moderating role of family history of substance use on the mediational associations between age, selective EF components, and QoL domains. From the moderated mediation analyses, it was found that inhibition more strongly explained the negative link of age with psychological, social, and environmental QoL in substance abuser men having a positive compared to those having a negative family history of substance use. A likely justification is that inhibition scores were significantly different between substance abusers having a positive compared to those having a negative family history. The substance abusers with a positive family history clearly presented poorer scores. Although an age related decline in EF may occur in response to substance use in young men, it is possible that this decline speeds up and becomes more apparent in substance abusers with a positive history of substance use, which may have led to different mediational explanations of the age-QoL link across two studied groups. The findings from Shoal and Giancola [25] support the same that the high risk group of adolescent boys with a positive family history scored lower on EF tasks compared to the low risk group with a negative family history and that the family history moderated the negative correlation between frequency of substance use and EF. This empirical evidence can be regarded as a remote support for the present study because the direct supporting evidence for the conditional mediated associations across groups with a positive versus negative family history of substance use is not present in the previous literature.

\section{Limitations, Implications, and Future Directions}

This is a cross sectional quantitative study which has provided a preliminary evidence of age related weakening of selective EF abilities and decreasing QoL starting from young adulthood years in a sample of young illicit substance abuser men from a patriarchal culture in South Asian region. The findings provide a clue that the studied population becomes a vulnerable group which has weakening status of mental capacities and poorer QoL associated with substance use, and requires health and support services. Moreover, family history of substance use adds further susceptibility to weakening cognitive capacities. The empirical information on these factors, which are supplementary determinants of effective intervention, may guide intervention planners towards improved treatment planning and clinical practice. The findings suggest that policy makers, rehabilitation centers, psychologists, and health care providers can benefit from the findings in formulating policies, planning better treatment options, and provision of psychological care services for young substance user men. The increasing age as a determinant of substance abusers' inhibitory capacities and QoL may highlight that services should be customized to meet their changing needs and to reduce their increasing vulnerability. The findings also offer an avenue to provide executive functioning training to these individuals which in turn would have better implications for their QoL.

The study is significant in that it has evaluated the role of aging in association with cognitive and functional limitations, which is an emerging area of investigation for developmental researchers. Assessing these objectives on substance abuser populations becomes imperative given the evidence that an increasing number of substance abusers are surviving into older age [35]. However, the generalizability of the finding would be limited to only population of illicit substance abuser men living in the studied region. Also, the study had a relatively small sample of men, and did not include women and middle-aged and older men, reflecting the low prevalence and accessibility to women. The vulnerability of later groups to aging and substance abuse may vary due to different needs, responsibilities, experiences, and access to treatment services. The study provides avenues to future researchers to conduct longitudinal studies with larger and variant ageing cohorts of substance abusers representative of gender and social status variations from wider geographical regions to be confident on the causal associations between age related decline in $\mathrm{EF}$ and QoL.

\section{Conclusion}

To conclude, findings from the study revealed that i) age was inversely associated with psychological, social, and environmental QoL among young illicit substance abuser men; and ii) inhibition strongly mediated the negative age-QoL link among substance abuser men having a positive compared to those having a negative family history of substance use. Thus, to improve QoL and reduce the burden of substance abuse in aging substance abuser men, it is important to customize the intervention plans to cater their transforming needs with increasing age and to reduce their increasing vulnerability. Also, the findings highlight the importance of training to improve neuropsychological functions and particularly inhibition ability for better implications for their QoL. In a long run, preventing substance abuse problem on a large scale seems essential to decrease the negative consequences of family history of substance use on executive function development in descendants, which in turn would lead better QoL outcomes. 


\section{Declarations}

Ethics approval and consent to participate. Ethical approval was obtained from the Departmental research Review Committee, XXX University. Consent to participate in the study was also obtained from the participants.

Consent for publication. All authors extend their consent for publication of this manuscript. Also, the participants were informed that their individual data would not be disclosed. They extended their consent for publication of the research results based on the data obtained from them.

Availability of data and materials. Data from this study will be made available when required.

Competing interests. The authors report no conflicts of interest.

\section{Funding. NA}

Authors' contributions. The authors alone are responsible for the content and writing of this paper. All authors contributed significantly in the paper.

\section{References}

1. United Nations Office on Drugs and Crime. World Drug Report. Conclusions and Policy Implications. 2018. https://www.unodc.org/wdr2018/prelaunch/WDR18_Booklet_1_EXSUM.pdf

2. World Health Organization. (1998). Programme on mental health: WHOQOL user manual. http://www.who.int/iris/handle/10665/77932\#sthash.jCXbuNFW.dpuf. Accessed 29 April 2020.

3. Rojas AJ, Lozano O, Foresti K, et al. Comparison and concordance of health-related quality of life tests among substance users. Health Qual Life Outcomes. 2015; 13:186. Doi:10.1186/s12955-015-0364-8

4. Muller AE, Skurtveit S, Clausen T. Many correlates of poor quality of life among substance users entering treatment are not addiction-specific. Health Qual Life Outcomes. 2016; 14: 39. Doi:10.1186/s12955-016-0439-1

5. Smith KW, Larson MJ. Quality of life assessments by adult substance abusers receiving publicly funded treatment in Massachusetts. Am J Drug Alcohol Abuse. 2003; 29(2): 323-335. Doi:10.1081/ada-120020517.

6. Tracy EM, Laudet AB, Min MO, et al. Prospective patterns and correlates of quality of life among women in substance abuse treatment. Drug Alcohol Depend. 2012; 124(3): 242-249. Doi:10.1016/j.drugalcdep.2012.01.010

7. Figueira HA, Figueira JA, Mello D, Dantas EHM. Quality of life throughout ageing. Acta Medica Lituanica. 2008; 15(3): 169-172. Doi:10.4236/health.2012.42014

8. Bowling A. Ageing Well: Quality of Life in Old Age. Maidenhead: Open University Press; 2005.

9. Netuveli G, Wiggins R, Hildon Z, Montgomery SM, Blane D. Quality of life at older ages: Evidence from the English Longitudinal Study of Ageing (wave 1). J Epidemiol Community Health. 2006; 60(4): 357-363. Doi:10.1136/jech.2005.040071

10. Bargagli A, Hickman M, Davoli M, et al. Drug related mortality and its impact on adult mortality in eight European countries. Eur J Public Health Advanc. 2006; 16(2): 198-202. Doi:10.1093/eurpub/cki168

11. Roe B, Beynon C, Pickering L, Duffy P. Experiences of drug use and ageing: health, quality of life, relationship and service implications. J Adv Nurs. 2010; 66(9): 1968-1979. Doi:10.1111/j.1365-2648.2010.05378.x

12. Barbosa-Leiker C, Campbell ANC, Pavlicova M, et al. Substance Use and Mental Health in Emerging Adult Vs Older Adult Men and Women With Opioid Use Disorder. Am J Addict 2020; 29: 536-542.

13. Hagen E, Erga AH, Hagenc KP, Nesvåg SM, McKayd JR, Lundervolde AJ, Walderhaug E. Assessment of Executive Function in Patients With SubstanceUse Disorder: A Comparison of Inventory-and Performance-Based Assessment. J Sub Abuse Treatment. 2016; 66: 1-8. Doi:10.1016/j.jsat.2016.02.010

14. Elderkin-Thompson V, Ballmaier M, Hellemann G, Pham D, Kumar A. Executive function and MRI prefrontal volumes among healthy older adults. Neuropsychol. 2008; 22: 626-637. Doi:10.1037/0894-4105.22.5.626.

15. Fatima S, Khan M, Rosseli M, Ardila A. Age, executive functioning, and decision-making styles in adults: A moderated mediation model. Aging Neuropsychol Cogn. 2020; 27(3): 338-350. Doi:10.1080/13825585.2019. 1614142.

16. Peng H, Gao Y, Mao X. The roles of sensory function and cognitive load in age differences in inhibition: Evidence from the Stroop task. Psychol Aging. 2017; 32(1): 42-50. Doi:10.1037/pag0000149.

17. Rypma B, Prabhakaran V, Desmond El, Gabrieli EDJ. Age differences in prefrontal cortical activity in working memory. Psychol Aging. $2001 ; 16: 371-384$. Doi:10.1037/0882-7974.16.3.371

18. Salmani A, Pilehroud MN, Jammali M, Monacis L. Comparison of executive functions in addicted young people who referred to addiction treatment camps with students. Cogent Psychol. 2020; 7(1). Doi:10.1080/23311908.2020.1754108

19. Fatima S, Shahid Z. Conditional indirect relations between executive functions, emotion regulation, and Machiavellianism in young men and women. Pers Individ Dif. 2020; 165: Article 110140. Doi:10.1016/j.paid.2020.110140

20. Fatima S, Sheikh H. Adolescent Aggression as Predicted from Parent-Child Relationships and Executive Functions. Am J Psychol. 2016; 129(3): 283294. Doi:10.5406/amerjpsyc.129.3.0283.

21. Kahl U, Callsen S, Beck S, et al. Health-related quality of life and self-reported cognitive function in patients with delayed neurocognitive recovery after radical prostatectomy: a prospective follow-up study. Health Qual Life Outcomes. 2021; 19: 64. doi:10.1186/s12955-021-01705-z. 
22. Parsons TD, Braaten AJ, Hall, CD, et al. Better quality of life with neuropsychological improvement on HAART. Health Qual Life Outcomes. 2006 ; 4:11. Doi:10.1186/1477-7525-4-11.

23. Stern A, Pollak Y, Bonne O, Malik E, Maeir A. The Relationship between Executive Functions and Quality of Life in Adults with ADHD. J Attention Disord. 2013; 21(4): 323-330. Doi:10.1177/1087054713504133.

24. Kelder RO, Ensink JBM, Overbeek G, Maric M, Lindauer RJL. Executive function as a mediator in the link between single or complex trauma and posttraumatic stress in children and adolescents. Qual Life Res. 2017; 26:1687-1696. Doi:10.1007/s11136-017-1535-3

25. Shoal GD, Giancola PR. Executive cognitive functioning, negative affectivity, and drug use in adolescent boys with and without a family history of a substance use disorder. J Child Adolesc Subst Abuse. 2001; 10(4): 111-121. Doi:10.1300/J029v10n04_11

26. Tapert SF, Brown SA. Substance dependence, family history of alcohol dependence and neuropsychological functioning in adolescence. Addiction. 2000; 95: 1043-1053. Doi:10.1046/j.1360-0443.2000.95710436.x.

27. Aslam N. Substance use among Pakistani youth - Current situation, preventive and intervention strategies. Pak J Med Res. 2019; 58(2): 44-45.

28. Delis DE, Kaplan E, Kramer JH. Delis Kaplan executive function system. USA: The Psychological Corporation; 2001.

29. Khan MN, Akhter MS, Ayub M, Alam S, Laghari NU. Translation and validation of quality of life scale, the brief version. J Coll Physicians Surg Pak. 2003; 13(2): 98-100. Doi:10.02.2003/jcpsp.98100

30. Preacher KJ, Hayes AF. Asymptotic and resampling strategies for assessing and comparing indirect effects in multiple mediator models. Behav Res Methods. 2008; 40(3): 879-891. Doi:10.3758/BRM.40.3.879.

31. Fatima S, Jibeen T. Interplay of Self-efficacy and Social Support in Predicting Quality of Life in Cardiovascular Patients in Pakistan. Community Ment Health. 2019; 55(5): 855-864. Doi:10.1007/s10597-018-0361-6.

32. Campos ACV, Ferreira EFE, Vargas AMD, Albala C. Aging, gender and quality of Life (AGEQOL) study: Factors associated with good quality of life in older Brazilian community-dwelling adults. Health Qual Life Outcomes. 2014; 12(166): 2-11. Doi:10.1186/s12955-014-0166-4.

33. Park DC, Lautenschlager G, Hedden T, Davidson NS, Smith AD, Smith PK. Models of visuospatial and verbal memory across the adult life span. Psychol Aging. 2002; 17: 299-320. Doi:10.1037/0882-7974.17.2.299

34. Fatima S, Jamil M, Ardila A. Cognitive control and criminogenic cognitions in south Asian gamblers. J Gambl Stud. 2019; $35(2): 501-516$. Doi:10.1007/s10899-018-9805-8.

35. Gossop M, Moos R. Substance misuse among older adults: a neglected but treatable problem. Addiction. 2008; 103: 347-348. Doi:10.1111/j.13600443.2007.02096.x.

\section{Tables}

Table 1 Demographic Characteristic of the Sample

\begin{tabular}{|c|c|c|c|}
\hline \multirow[t]{2}{*}{ Variables } & Full sample(N=212) & $\mathrm{FH}-(\mathrm{N}=107)$ & $\mathrm{FH}+(\mathrm{N}=105)$ \\
\hline & Mean(SD) & Mean(SD) & Mean(SD) \\
\hline Age & $27.61(5.38)$ & $26.64(4.92)$ & $28.59(5.76)$ \\
\hline Education $^{a}$ & $11.22(2.69)$ & $11.71(2.68)$ & $10.71(2.61)$ \\
\hline Onset Age & $22.29(3.58)$ & 22.92(3.59) & $21.65(3.48)$ \\
\hline Duration of substance use & $4.66(3.63)$ & $3.66(3.59)$ & $5.67(3.40)$ \\
\hline \multirow[t]{3}{*}{ Socioeconomic status ${ }^{b}$} & Low $=103$ & Low $=54$ & Low $=49$ \\
\hline & Middle=92 & Middle $=44$ & Middle $=48$ \\
\hline & High $=17$ & High $=9$ & High $=8$ \\
\hline \multirow[t]{3}{*}{ Severity of substance use ${ }^{c}$} & Low $=20$ & Low $=11$ & Low $=9$ \\
\hline & Moderate $=133$ & Moderate $=69$ & Moderate $=64$ \\
\hline & High $=59$ & High $=27$ & High $=32$ \\
\hline \multirow[t]{2}{*}{ Number of Substances used } & One $=58$ & One=31 & One=27 \\
\hline & Multi $=154$ & Multi $=73$ & Multi=81 \\
\hline
\end{tabular}

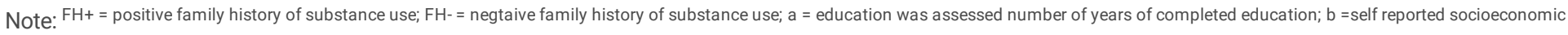
status; $c=$ severity index of substance use was taken from patient profile.

Table 2 Descriptive Statistics and Group Differences on Study Variables between Substance Abusers with a Positive or Negative Family History of Substance Use 


\begin{tabular}{|lllllll|}
\hline Variable & \multicolumn{2}{l}{ Full sample (N=212) } & & FH - (N=107) & FH+(N=105) & t value \\
\hline & Mean(SD) & Alpha & Range & Mean (SD) & Mean (SD) & \\
\hline Inhibition Ta & $265.11(110.71)$ & .93 & $10-397$ & $280.72(98.48)$ & $249.2(120.31)$ & $2.09^{*}$ \\
\hline Inhibition Ea & $89.01(29.10)$ & .95 & $4-117$ & $100.24(14.46)$ & $77.58(35.04)$ & $6.17^{* * *}$ \\
\hline Cognitive Flexibility & $15.36(6.93)$ & .84 & $4-28$ & $16.81(6.76)$ & $13.89(6.82)$ & $3.13^{* *}$ \\
\hline Physical QOL & $17.96(2.61)$ & .73 & $13-26$ & $17.66(2.63)$ & $18.26(2.57)$ & -1.69 \\
\hline Psychological QOL & $14.83(3.02)$ & .72 & $10-23$ & $15.72(2.71)$ & $13.91(3.05)$ & $4.56^{* * *}$ \\
\hline Social QOL & $7.04(2.11)$ & .70 & $4-13$ & $7.45(2.11)$ & $6.62(2.03)$ & $2.92^{\star *}$ \\
\hline Environmental QOL & $17.85(4.42)$ & .71 & $12-31$ & $19.32(4.36)$ & $16.34(3.95)$ & $5.17 * * *$ \\
\hline GQOL & $1.87(.85)$ & - & $1-4$ & $2.07(.89)$ & $1.66(.74)$ & $3.68^{* * *}$ \\
\hline GH & $2.28(.92)$ & - & $1-5$ & $2.69(.93)$ & $1.87(.69)$ & $7.28^{* * *}$ \\
\hline
\end{tabular}

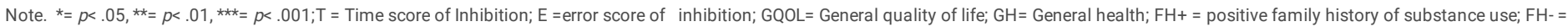
negtaive family history of substance use; $a=$ time and error scores on inhibition measure are reversed

Table 3 Correlation between Age, Inhibition, Cognitive Flexibility, and Quality of Life Domains

\begin{tabular}{|c|c|c|c|c|c|c|c|c|}
\hline Variables & 5 & 6 & 7 & 8 & 9 & 10 & 11 & 12 \\
\hline 1.Education & $.55^{\star \star \star}$ & $.61^{\star \star \star}$ & -.03 & $.20 * \star$ & .04 & $.19 * \star$ & $.25^{\star \star \star}$ & $.17 *$ \\
\hline 2.DurationSA & 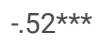 & $-.35^{\star \star \star}$ & $.20 \star *$ & $-.16 \star$ & -.03 & $-.16^{\star}$ & $-.28 * \star \star$ & $-.21 \star \star$ \\
\hline 3.Onset age & $.24^{\star \star \star}$ & .01 & $.38 \star \star \star$ & .13 & .05 & .13 & $.26^{\star \star \star}$ & 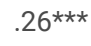 \\
\hline 4.Age & $-.58 * \star \star$ & $-.33 * \star \star$ & -.12 & $-.43 * \star \star$ & $-.30 * \star$ & $-.23 \star \star$ & $-.22 * \star$ & $-.22 * \star$ \\
\hline 5. Inhibition ${ }^{a}$ & - & $.62^{\star \star \star}$ & $.23^{\star \star}$ & $.50 * \star \star$ & $.43^{\star \star \star}$ & 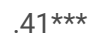 & $.18 *$ & 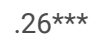 \\
\hline 6. Cog Flex & & - & .07 & $.35^{\star \star \star}$ & $.14^{\star}$ & $.20 \star \star$ & $.38 * \star \star$ & $.29 * \star \star$ \\
\hline 7.Ph.QoL & & & - & $.67 * \star \star$ & $.53 \star \star \star$ & 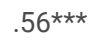 & .03 & $-.20 * \star$ \\
\hline 8.Psy.QoL & & & & - & $.50 \star \star \star$ & 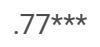 & $.40 * \star \star$ & .01 \\
\hline 9.S.QoL & & & & & - & 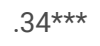 & $.17 *$ & .13 \\
\hline 10.Env.QoL & & & & & & - & $.16^{*}$ & .03 \\
\hline 11.GQoL & & & & & & & - & $.15^{\star}$ \\
\hline 12.GH & & & & & & & & - \\
\hline
\end{tabular}

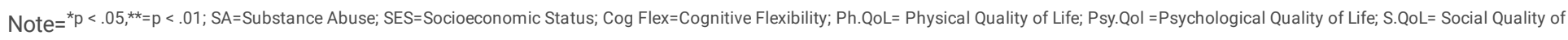
Life; Env.QoL=Environmental Quality of Life; GQoL= General Quality of Life; GH= General Health; a = Time and error scores on inhibition measure are reversed

Table 4 Moderated Mediation Models Representing Conditional Indirect Associations between Age, Inhibition, and QOL Domains 


\begin{tabular}{|c|c|c|c|c|c|c|c|c|}
\hline \multirow[t]{3}{*}{ Predictors } & \multicolumn{8}{|c|}{ Outcome Variables } \\
\hline & \multirow{2}{*}{$\begin{array}{l}\text { Model } 4 \\
\text { Psy.QoL }\end{array}$} & \multicolumn{2}{|l|}{ Model 7} & \multirow{2}{*}{$\begin{array}{l}\text { Model } 4 \\
\text { Social QoL }\end{array}$} & \multicolumn{2}{|l|}{ Model 7} & \multirow{2}{*}{$\begin{array}{l}\text { Model } 4 \\
\text { Env.QoL }\end{array}$} & \multirow{2}{*}{$\begin{array}{l}\text { Model } 7 \\
\text { Inhibitiol }\end{array}$} \\
\hline & & Inhibition ${ }^{\mathrm{b}}$ & Cog.Flex. ${ }^{b}$ & & Inhibition ${ }^{\mathrm{b}}$ & Cog.Flex. ${ }^{b}$ & & \\
\hline Education & $.03(.03)$ & $.16(.02)^{\star \star \star \star}$ & $.23(.02)^{\star \star \star \star}$ & $-.03(.03)$ & $.16(.02)^{\star \star \star}$ & $.24(.02)^{\star \star \star}$ & $.01(.03)$ & $.15(.02)^{\star}$ \\
\hline $\begin{array}{l}\text { Duration } \\
\text { SA }\end{array}$ & $.13(.02)^{\star \star \star}$ & $.04(.02)$ & $.07(.02)^{\star \star}$ & $.12(.02)^{\star \star \star}$ & $.04(.02)^{\star}$ & $.06(.02)^{\star}$ & $.03(.03)$ & $.04(.02)^{\star}$ \\
\hline Age & 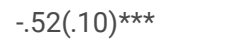 & $-.19(.07)^{\star}$ & $-.50(.10)^{\star \star \star}$ & $-.32(.10)^{\star \star}$ & $-.20(.07)^{\star \star}$ & $-.48(.10)^{\star \star \star}$ & $-.04(.11)$ & $-.21(.08)$ \\
\hline Inhibition & $.37(.09)^{\star \star \star \star}$ & - & - & $.60(.09)^{\star \star \star}$ & - & - & $.50(.10)^{\star \star \star}$ & - \\
\hline $\begin{array}{l}\text { cognitive } \\
\text { flexibility }\end{array}$ & $.04(.08)$ & - & - & $-.14(.08)$ & - & - & $-.12(.09)$ & - \\
\hline $\mathrm{FH}^{\mathrm{c}}$ & - & $-.31(.08)^{\star \star \star}$ & $-.13(.10)$ & - & $-.30(.08)^{\star \star \star}$ & $-.16(.10)$ & - & $-.29(.08)$ \\
\hline Age X FH & - & $-.70(.08)^{\star \star \star}$ & $.20(10)$ & - & 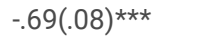 & $.20(10)$ & - & $-.68(.08)$ \\
\hline $\mathrm{R}^{2}$ & .37 & .70 & .48 & .32 & .69 & .46 & .18 & .69 \\
\hline Model fit & $(5,204) 23.65^{\star \star \star}$ & $(5,206) 90.59 * \star \star$ & $(5,206) 37.08^{\star \star \star}$ & $(5,206) 19.26^{\star * \star}$ & $(5,206) 90.53^{\star \star \star}$ & $(5,206) 35.61^{\star \star \star}$ & $(5,204) 8.78^{\star \star \star}$ & $(5,206) 8$ \\
\hline $\begin{array}{l}\text { Total } \\
\text { effect }\end{array}$ & $-.75(.09)$ & & & $-.62(.09)$ & & & $-.30(.10)$ & \\
\hline $\begin{array}{l}\text { Direct } \\
\text { effect }\end{array}$ & $-.52(.10)$ & & & $-.32(.10)$ & & & $-.04(.11)$ & \\
\hline $\begin{array}{l}\text { Indirect } \\
\text { effect }\end{array}$ & $-.23(.06)$ & & & $-.30(.06)$ & & & $-.27(.08)$ & \\
\hline $\begin{array}{l}\text { Indirect } \\
\text { effect } \\
\text { (inhibition) }\end{array}$ & \multicolumn{3}{|c|}{$-.21(.06)$, Sobel $z=-3.72^{\star \star \star}$} & \multicolumn{3}{|c|}{ 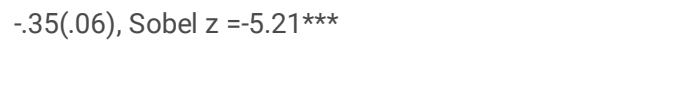 } & \multicolumn{2}{|c|}{$-.31(.09)$, Sobel $z=-4.22^{\star \star \star}$} \\
\hline $\begin{array}{l}\text { Indirect } \\
\text { effect (cog. } \\
\text { Flex.) }\end{array}$ & \multicolumn{3}{|c|}{$-.02(.03)$, Sobel z = -0.54} & \multicolumn{3}{|c|}{$.05(.03)$, Sobel z = 1.59} & \multicolumn{2}{|c|}{$.04(.03)$, Sobel z = 1.18} \\
\hline \multirow{2}{*}{$\begin{array}{l}\text { Conditional } \\
\text { Indirect } \\
\text { effect } \\
\text { (inhibition) }\end{array}$} & \multicolumn{3}{|l|}{$\mathrm{FH}+=-.33(.09)$} & \multicolumn{3}{|l|}{$\mathrm{FH}+=-.54(.08)$} & \multicolumn{2}{|l|}{$\mathrm{FH}+=-.45(.11)$} \\
\hline & \multicolumn{3}{|l|}{$\mathrm{FH}-=-.07(.03)$} & \multicolumn{3}{|l|}{$\mathrm{FH}-=-.12(.05)$} & \multicolumn{2}{|l|}{$\mathrm{FH}-=-.11(.05)$} \\
\hline \multirow{2}{*}{$\begin{array}{l}\text { Conditional } \\
\text { Indirect } \\
\text { effect (cog. } \\
\text { Flex.) }\end{array}$} & \multicolumn{3}{|l|}{$\mathrm{FH}+=-.01(.02)$} & \multicolumn{3}{|l|}{$\mathrm{FH}+=.04(.03)$} & \multicolumn{2}{|l|}{$\mathrm{FH}+=.03(.03)$} \\
\hline & \multicolumn{3}{|l|}{$\mathrm{FH}-=-.02(.04)$} & \multicolumn{3}{|l|}{$\mathrm{FH}-=.07(.04)$} & \multicolumn{2}{|l|}{$\mathrm{FH}-=.06(.05)$} \\
\hline
\end{tabular}

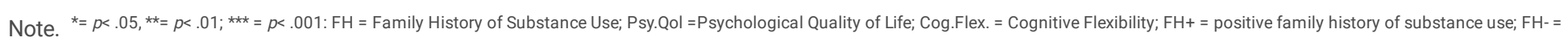

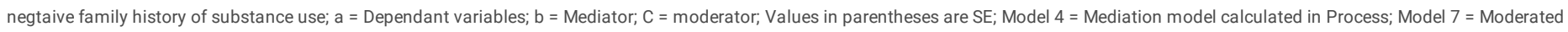
mediation model calculated in Process.

\section{Figures}




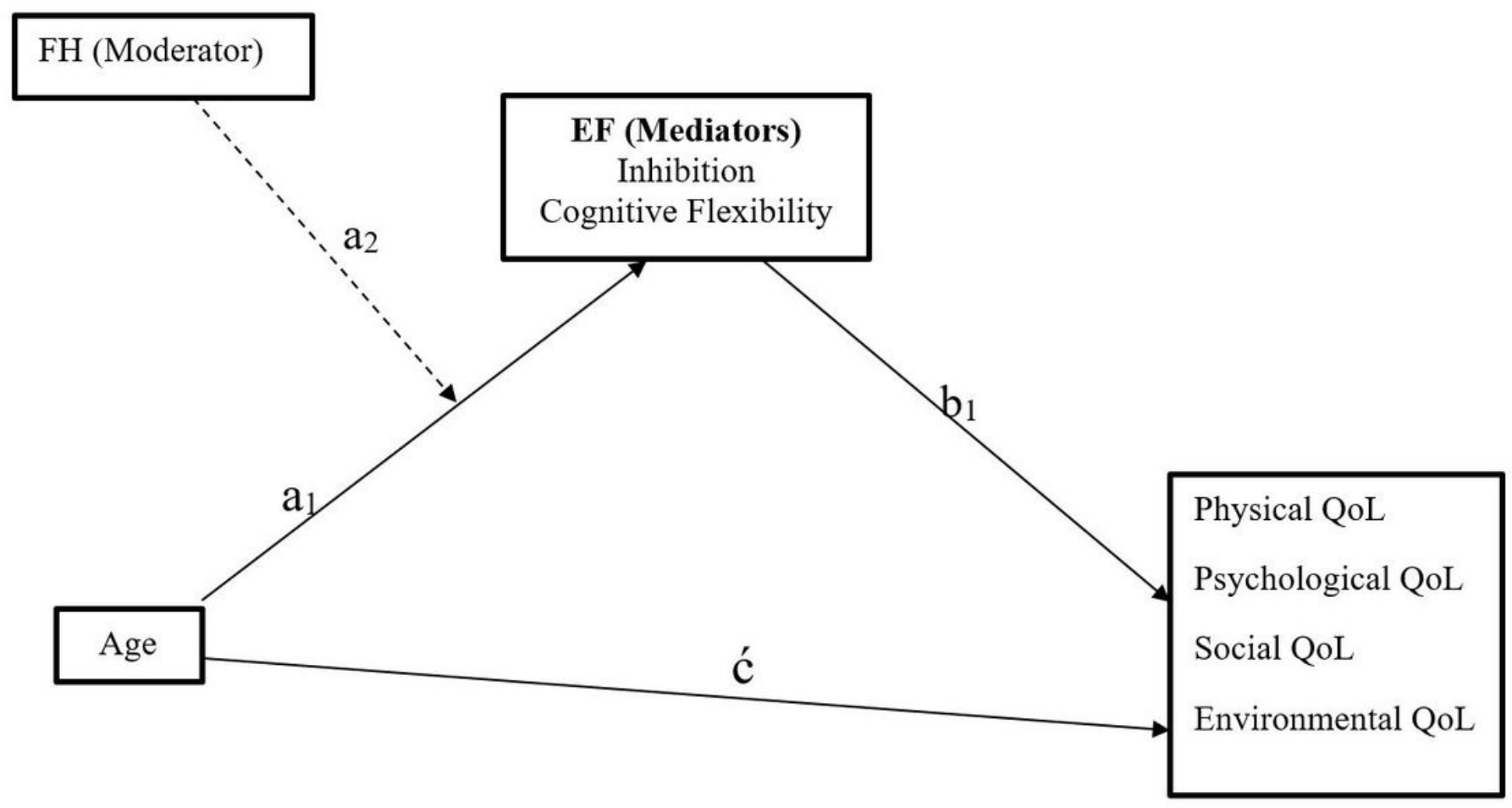

Figure 1

Hypothesized Moderated mediation model assessing the mediating role of executive functions in association between age and quality of life domains and the moderating role of family history of substance use

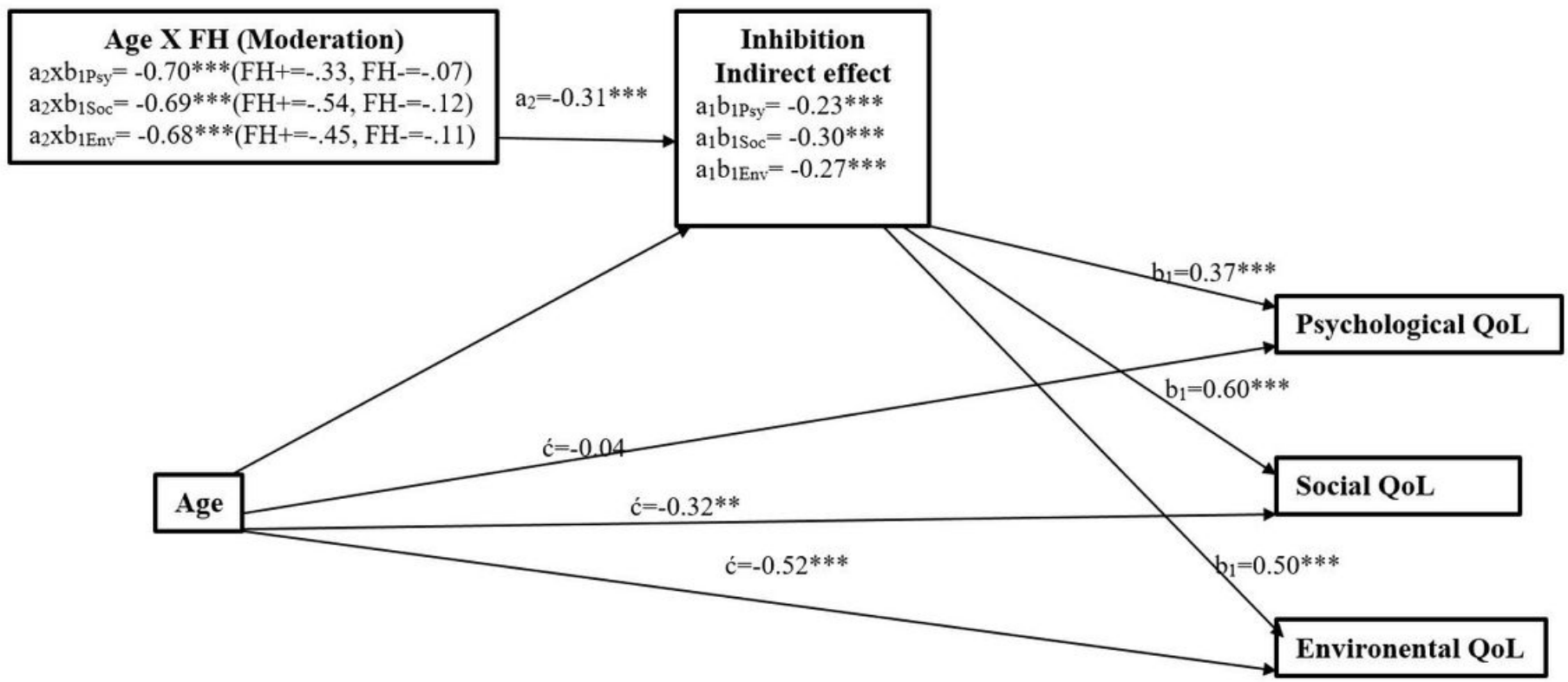

Figure 2

Moderated mediation model showing conditional indirect associations between age, inhibition, and QoL domains across participants with positive and negative family history of substance use; Values shown are regression weights Note: ${ }^{*}=p<.05,{ }^{* *}=p<.01$; $a 2 x b 1$ Psy= Moderation a1b1Psy= Indirect effect ć= Direct effect 